\title{
Design and dynamic analysis of a novel double-swing vane compressor for electric
}

\section{vehicle air conditioning systems}

Xu Yang*, Chen Dong and Zongchang Qu.

School of Energy and Power Engineering, Xi'an Jiaotong University, 28 Xianning West Road, Xi'an, 710049, China.

*Corresponding author. Email: yangzx@ mail.xjtu.edu.cn.

\begin{abstract}
This paper presents a novel double-swing vane compressor (DSVC) for use in electric vehicle air conditioning systems. The design and work principle of the DSVC are introduced, and the dynamics and mechanical efficiency of the mechanism are theoretically formulated and analysed. Under the same operating conditions and dimensions, the theoretical volumetric flow rate of the DSVC is about 1.6 times that of the swing vane compressor (SVC) with a single swing vane and the mechanical efficiency of the DSVC is also greater than that of the SVC. The design of the double-swing vanes improves the load fluctuations on the eccentric and shaft bearings and enhances the operating smoothness of the compressor. Overall, the assessment of the structure and dynamics of the DSVC shows that the DSVC has the advantages of high efficiency, light weight and simple component geometries, which make it well suited to the requirements of electric vehicle air conditioning systems.
\end{abstract}

\section{Keywords}

Design, rotary compressor, dynamic model, mechanical efficiency, friction loss.

\section{Introduction}

Air conditioning system is one of indispensable accessories in modern vehicles, which is utilized to provide a comfortable driving environment. Compared with the combustion engine driven vehicle, the electric vehicle 
makes a big difference in the operation of the air conditioning system due to the change in power supply. As the key component in air conditioning systems based on vapour compression, the compressor needs to suit the operational conditions of electric vehicles. Because of the limited battery capacity of electric vehicles, the compressor unit needs to be more efficient, smaller in volume and lighter in weight to reduce the electrical energy consumption (Qi, 2014). Since the compressor is independently driven by an electric rotor instead of belt driven by a combustion engine, the rotational speed of the compressor and the work capacity of the air conditioning system can be easily adjusted by a variable speed motor. In this case, the compressor is also required to work at variable speeds in a wide operational range (Wang et al., 2016).

Among the compressors developed for the traditional vehicle air conditioning systems, rotary type compressors exhibit better performance in electric vehicles compared to reciprocating type compressors. Although the reciprocating compressors, such as the wobble plate compressor (Cuevas et al., 2008; Tian et al., 2004) and swash plate compressor (Tian et al., 2006; Zhang and Wang, 2012), are demonstrated to have excellent performance in traditional vehicle air conditioning systems, issues of noise and friction arising from the high operating speed limit their application in electric vehicles. In contrast, the rotary type compressors are normally able to operate under high speed conditions. For example, the scroll compressor is considered to be suitable for application in electric vehicles due to its high efficiency, small volume and light weight (Cuevas et al., 2012; Nam et al., 2015). However, this type of compressor has a higher manufacture cost because its main components are structurally complex.

To contribute to the development of a lower cost rotary compressor for electric vehicle air conditioning systems, a novel double-swing vane compressor (DSVC) is introduced in this paper. This type of compressor is designed on the basis of the swing vane compressor (SVC) presented by Hu et al. (2013), which is structurally simple and easy to manufacture and also has a higher mechanical efficiency. Compared with the SVC, the work 
capacity of the DSVC is significantly increased under the same operating conditions and dimensions by adding an additional vane in the mechanism. This allows significant reductions in the volume and weight of the compressor unit, which closely matches the requirements for electric vehicles. In this paper, the design and work principle of the DSVC are introduced and the dynamics of the DSVC are theoretically modelled. Based on the simulations of the dynamic models, the dynamic characteristics and mechanical efficiency of the DSVC are analysed and discussed.

\section{Design and work principle}

Fig. 1 shows a schematic of the main assembly of a hermetic DSVC without the eccentric motor and housing. It

can be observed that the DSVC essentially consists of a rotor, cylinder and two swing vanes. The rotor is assembled with an eccentric shaft that is supported on two journal bearings such that the outer surface of the rotor is tangent to the inner surface of the cylinder. One end of the upper vane is inserted into the vane slot on the rotor while the other end is jointed with the cylinder. One end of the lower vane is jointed with the rotor while the other end is inserted into the guide way assembled with the cylinder. Unlike the SVC with a single-swing vane (Hu et al., 2013), the crescent chamber trapped within the cylinder and rotor is divided by the two vanes into two work chambers, namely the former work chamber and the latter work chamber. Each work chamber is connected with a suction valve assembly and a discharge valve assembly. During the operation of the DSVC, the eccentric shaft drives the rotor such that the tangent point moves along the inner wall of the cylinder. As the rotor rotates, the upper vane swings around the centre of the vane joint on the cylinder. At the same time, the lower vane swings around the centre of the vane joint on the rotor and slides in the guide way. Due to the motion of the components, the volume of each chamber varies periodically, which results in the suction, compression and discharge of the work fluids. 
Compared to the design of the SVC, a significant modification of the DSVC is that the trapped volume within the rotor and cylinder is divided in half by the two vanes, which results in significant changes in the work process and suction volume during each shaft revolution. Fig. 2 shows the schematic of the work principle of the DSVC, where the rotation of the shaft is in the clockwise direction and $\varphi$ is defined as the shaft angle. As shown in Fig. 2, for an element volume of each work chamber, one and half shaft revolutions $(\varphi=0 \sim 3 \pi)$ are needed to complete the whole work cycle including the suction, compression and discharge processes. For the former work chamber, the suction process starts from a rotor angle of $\varphi=0$ and the element volume gradually increases until the rotor angle nears $\varphi=3 \pi / 2$ where it reaches its maximum value. Then, the element volume gradually decreases until the rotor angle of $\varphi=3 \pi$, which results in the compression and discharge processes. For the latter work chamber, there is an angle difference of $\pi$ for the work cycle of the element volume, which begins at $\varphi=\pi$ and ends at $\varphi=4 \pi$. Fig. 3 shows the variations in the element volume and pressure for the former and latter work chambers during a work cycle. This calculation is based on a DCV prototype, the main dimensions of which are given in Table 1. It can be observed that the varying trends of the element volumes for the former and latter work chambers are almost same and their maximum values are equivalent.

As shown in Fig. 2, in the shaft angle range of $0 \sim 2 \pi$, the volume of work fluids that enters into the former work chamber is equal to the maximum chamber volume $V_{\max }$. Similarly, in the shaft angle range of $\pi \sim 3 \pi$, the volume of work fluids that enters into the latter work chamber is also equal to $V_{\max }$. Because the chamber volumes vary periodically, the effective suction volume of the compressor during a shaft revolution can be considered to be equal to $2 V_{\max }$, which is greater than the volume of the crescent chamber trapped by the rotor and cylinder walls. This means that the effective suction volume of the DSVC is greater than that of an SVC with the same dimension of rotor and cylinder. According to the dimensions given in Table 1 , the suction volume of the SVC is $17.59 \mathrm{~cm}^{3}$ while the suction volume of the DSVC is $28.77 \mathrm{~cm}^{3}$, or about 1.6 times that of 
the SVC, by giving a theoretical volumetric swept volume of $5.18 \mathrm{~m}^{3} / \mathrm{h}$ for the vehicle air conditioning system at the shaft speed of $3000 \mathrm{rpm}$. In this way, it can be concluded that the design of the double-swing vanes in the DSVC extends the use of the trapped volume between the rotor and cylinder and brings about a larger work capacity for the DSVC. In other words, this characteristic of the DSVC make it possible to reduce the volume and weight of the compressor, making it well suited for application in electric vehicle air conditioning systems.

\section{Dynamic models}

\subsection{Dynamic model of the upper vane}

As shown in Fig. 4(a), during the operation of the DSVC, the upper vane is driven by the rotor and swings around its joint centre A in the plane of the Cartesian coordinate system OXY. On the OXY coordinates, $\mathrm{AO}_{1}$ is the centre line of the upper vane. The included angle between axis $\mathrm{Y}$ and $\mathrm{AO}_{1}$ as well as the angular displacement of the upper vane can be expressed as a function of the shaft angle as follows,

$$
\theta_{\mathrm{A}}=\arcsin \left(\frac{e}{\left|\mathrm{AO}_{1}\right|} \sin \varphi\right)
$$

where

$$
\left|\mathrm{AO}_{1}\right|=\sqrt{\left(R_{\mathrm{cy}}+R_{\mathrm{A}}\right)^{2}+e^{2}-2 e\left(R_{\mathrm{cy}}+R_{\mathrm{A}}\right) \cos \varphi}
$$

in which $R_{\mathrm{cy}}$ is the radius of the cylinder, $R_{\mathrm{A}}$ is the radius of the upper vane joint and $e$ is the eccentricity.

As shown in Fig. 4(a), the forces and moments acting on the upper vane include the restriction forces at vane joint centres $F_{\mathrm{R}, \mathrm{A}}^{\mathrm{t}}$ and $F_{\mathrm{R}, \mathrm{A}}^{\mathrm{n}}$, the restriction forces and friction forces of the vane slot acting on the vane sides $F_{\mathrm{S}, \mathrm{A}}^{1}, \quad F_{\mathrm{S}, \mathrm{A}}^{2}, F_{\mathrm{F}, \mathrm{A}}^{1}$ and $F_{\mathrm{F}, \mathrm{A}}^{2}$, the pressure force caused by the pressure difference between the adjacent chamber $F_{\mathrm{P}, \mathrm{A}}$, the inertia forces $F_{\mathrm{I}, \mathrm{A}}^{\mathrm{t}}$ and $F_{\mathrm{I}, \mathrm{A}}^{\mathrm{n}}$ and the frictional moment at the vane joint $M_{\mathrm{F}, \mathrm{A}}$. The balance equation set for the above forces and the moment acting on the upper vane can be derived as follows, 


$$
\left\{\begin{array}{l}
F_{\mathrm{S}, \mathrm{A}}^{1}-F_{\mathrm{S}, \mathrm{A}}^{2}+F_{\mathrm{R}, \mathrm{A}}^{\mathrm{t}}=F_{\mathrm{I}, \mathrm{A}}^{\mathrm{t}}-F_{\mathrm{P}, \mathrm{A}} \\
F_{\mathrm{F}, \mathrm{A}}^{1}+F_{\mathrm{F}, \mathrm{A}}^{2}-F_{\mathrm{R}, \mathrm{A}}^{\mathrm{n}}=F_{\mathrm{I}, \mathrm{A}}^{\mathrm{n}} \\
\left(\left|\mathrm{AO}_{1}\right|-R_{\mathrm{ro}}\right) F_{\mathrm{S}, \mathrm{A}}^{1}-h_{\mathrm{A}} F_{\mathrm{S}, \mathrm{A}}^{2}=r_{\mathrm{A}} F_{\mathrm{I}, \mathrm{A}}^{\mathrm{t}}-\left(\left|\mathrm{AO}_{1}\right|-R_{\mathrm{ro}}-0.5|\mathrm{EF}|\right) F_{\mathrm{P}, \mathrm{A}}+M_{\mathrm{F}, \mathrm{A}}
\end{array}\right.
$$

where $h_{\mathrm{A}}$ is the length of the upper vane, $R_{\mathrm{ro}}$ is the radius of the rotor, $r_{\mathrm{A}}$ is the distance between the vane centroid $G_{A}$, and $A$, and $E$ and $F$, respectively, are the intersections of $A_{1}$ with the rotor circle and cylinder circle. Due to the complex geometry, it is difficult to formulate the distance of $|\mathrm{EF}|$. However, $|\mathrm{EF}|$ is easily evaluated from the coordinates of $\mathrm{E}$ and $\mathrm{F}$ on $\mathrm{OXY}$, which can be obtained by solving the equation sets of line $\mathrm{AO}_{1}$ and circles $\mathrm{O}$ and $\mathrm{O}_{1}$.

The inertia forces respectively are expressed as,

$$
\left\{\begin{array}{l}
F_{\mathrm{I}, \mathrm{A}}^{\mathrm{t}}=m_{\mathrm{A}} r_{\mathrm{A}} \alpha_{\mathrm{A}} \\
F_{\mathrm{I}, \mathrm{A}}^{\mathrm{n}}=m_{\mathrm{A}} r_{\mathrm{A}} \omega_{\mathrm{A}}^{2}
\end{array}\right.
$$

where $m_{\mathrm{A}}$ is the mass of the upper vane, and $\alpha_{\mathrm{A}}$ and $\omega_{\mathrm{A}}$ are the angular acceleration and angular velocity of the upper vane, respectively, which can be derived from the angular displacement formulated by Eq. (1).

The pressure force is expressed as,

$$
F_{\mathrm{P}, \mathrm{A}}=\left(p_{3}-p_{1}\right)|\mathrm{EF}| H
$$

where $p_{1}$ and $p_{3}$ respectively are the pressure in volumes 1 and 3 , and $H$ is the rotor length.

Due to the significant restriction forces of the vane slot and the sliding motion of the upper vane, the friction on the upper vane sides is most likely to be classified as boundary friction. Thus, the friction forces on the vane sides can be formulated as,

$$
\left\{\begin{array}{l}
F_{\mathrm{F}, \mathrm{A}}^{1}=\eta_{\mathrm{S}} F_{\mathrm{S}, \mathrm{A}}^{1} \\
F_{\mathrm{F}, \mathrm{A}}^{2}=\eta_{\mathrm{S}} F_{\mathrm{S}, \mathrm{A}}^{2}
\end{array}\right.
$$

where $\eta_{\mathrm{S}}$ is the friction coefficient, which is assumed to be a constant value of 0.15 as proposed by Yanagisawa and Shimizu (1985). 
Considering the rotation of the vane joint is oscillatory and it has a low angular velocity, boundary friction will most likely occur at the contact. The frictional moments at the vane joint can be expressed as follows,

$$
M_{\mathrm{F}, \mathrm{A}}=\eta_{\mathrm{J}} R_{\mathrm{A}} \sqrt{{F_{\mathrm{R}, \mathrm{A}}^{\mathrm{t}}+F_{\mathrm{R}, \mathrm{A}}^{\mathrm{n}}}^{2}}
$$

where $\eta_{\mathrm{J}}$ is the friction coefficient, which is assumed to be a constant value of 0.1 as proposed by Teh and Ooi (2009).

In the balance equation set of the upper vane given as Eq. (3), $F_{\mathrm{R}, \mathrm{A}}^{\mathrm{t}}, F_{\mathrm{R}, \mathrm{A}}^{\mathrm{n}}, F_{\mathrm{S}, \mathrm{A}}^{1}$ and $F_{\mathrm{S}, \mathrm{A}}^{2}$ are unknown forces. To solve these unknown forces, an additional equation is needed to construct a closed equation set. This equation is formulated from the rotor dynamics in section 3.3.

\subsection{Dynamic model of the lower vane}

As shown in Fig. 4(a), during the operation of the DSVC, the lower vane swings around the centre of guide way $\mathrm{C}$ while it slides through the guide way. The included angle between axis $\mathrm{Y}$ and $\mathrm{BC}$ and the angular displacement of the lower vane can be expressed as a function of the shaft angle as follows,

$$
\theta_{\mathrm{B}}=\arcsin \left(\frac{|\mathrm{AB}| e}{|\mathrm{BC}|\left|\mathrm{AO}_{1}\right|} \sin \varphi\right)
$$

The forces and moments acting on the lower vane include the restriction forces at vane joint centres $F_{\mathrm{R}, \mathrm{B}}^{\mathrm{t}}$ and $F_{\mathrm{R}, \mathrm{B}}^{\mathrm{n}}$, the restriction forces and frictional forces of the guide way acting on the vane sides $F_{\mathrm{S}, \mathrm{B}}$ and $F_{\mathrm{F}, \mathrm{B}}$, the pressure force $F_{\mathrm{P}, \mathrm{B}}$, the inertia forces $F_{\mathrm{I}, \mathrm{B}}^{\mathrm{t}}, F_{\mathrm{I}, \mathrm{B}}^{\mathrm{n}}, F_{\mathrm{I}, \mathrm{B}}^{\mathrm{k}}$ and $F_{\mathrm{I}, \mathrm{B}}^{\mathrm{r}}$, and the frictional resistance moments at the vane joint $M_{\mathrm{F}, \mathrm{B}}$ and the guide way $M_{\mathrm{F}, \mathrm{C}}$. The balance equation set of forces and moments acting on the lower vane can be derived as follows,

$$
\left\{\begin{array}{l}
F_{\mathrm{S}, \mathrm{B}}+F_{\mathrm{R}, \mathrm{B}}^{\mathrm{t}}=F_{\mathrm{P}, \mathrm{B}}+F_{\mathrm{I}, \mathrm{B}}^{\mathrm{t}}-F_{\mathrm{I}, \mathrm{B}}^{\mathrm{k}} \\
F_{\mathrm{F}, \mathrm{B}}+F_{\mathrm{R}, \mathrm{B}}^{\mathrm{n}}=-F_{\mathrm{I}, \mathrm{B}}^{\mathrm{r}}-F_{\mathrm{I}, \mathrm{B}}^{\mathrm{n}} \\
|\mathrm{BC}| F_{\mathrm{S}, \mathrm{B}}=(|\mathrm{BH}|-0.5|\mathrm{HI}|) F_{\mathrm{P}, \mathrm{B}}+r_{\mathrm{B}} F_{\mathrm{I}, \mathrm{B}}^{\mathrm{t}}-r_{\mathrm{B}} F_{\mathrm{I}, \mathrm{B}}^{\mathrm{k}}-M_{\mathrm{F}, \mathrm{B}}-M_{\mathrm{F}, \mathrm{C}}
\end{array}\right.
$$


where I and $\mathrm{H}$, respectively, are the intersections of $\mathrm{BC}$ with the rotor circle and cylinder circle, and $r_{\mathrm{B}}$ is the distance between the vane centroid $\mathrm{G}_{\mathrm{B}}$ and $\mathrm{B}$.

The inertia forces are expressed as,

$$
\left\{\begin{array}{l}
F_{\mathrm{I}, \mathrm{B}}^{\mathrm{t}}=m_{\mathrm{B}}\left(|\mathrm{BC}|-r_{\mathrm{B}}\right) \alpha_{\mathrm{C}} \\
F_{\mathrm{I}, \mathrm{B}}^{\mathrm{n}}=m_{\mathrm{B}}\left(|\mathrm{BC}|-r_{\mathrm{B}}\right) \omega_{\mathrm{C}}^{2} \\
F_{\mathrm{I}, \mathrm{B}}^{\mathrm{r}}=m_{\mathrm{B}} a_{\mathrm{r}, \mathrm{B}} \\
F_{\mathrm{I}, \mathrm{B}}^{\mathrm{k}}=2 m_{\mathrm{B}} \omega_{\mathrm{B}} v_{\mathrm{r}, \mathrm{B}}
\end{array}\right.
$$

where $m_{\mathrm{B}}$ is the mass of the lower vane, $\alpha_{\mathrm{C}}$ and $\omega_{\mathrm{C}}$ are the angular acceleration and angular velocity around $\mathrm{C}$, respectively, $a_{\mathrm{r}, \mathrm{B}}$ is the relative acceleration and $v_{\mathrm{r}, \mathrm{B}}$ is the relative velocity.

The pressure force is expressed as,

$$
F_{\mathrm{P}, \mathrm{B}}=\left(p_{2}-p_{3}\right) H|\mathrm{HI}|
$$

where $p_{2}$ is the pressure in volume 2 .

The friction force at the lower vane side is formulated as,

$$
F_{\mathrm{F}, \mathrm{B}}=\eta_{\mathrm{S}} F_{\mathrm{S}, \mathrm{B}}
$$

The frictional moments at the lower vane joint and guide way are respectively expressed as follows,

$$
\begin{gathered}
M_{\mathrm{F}, \mathrm{B}}=\eta_{\mathrm{J}} R_{\mathrm{B}} \sqrt{{F_{\mathrm{R}, \mathrm{B}}^{\mathrm{t}}+F_{\mathrm{R}, \mathrm{B}}^{\mathrm{n}}{ }^{2}}^{2}} \\
M_{\mathrm{F}, \mathrm{C}}=\eta_{\mathrm{J}} R_{\mathrm{C}} F_{\mathrm{S}, \mathrm{B}}
\end{gathered}
$$

where $R_{\mathrm{B}}$ is the radius of the lower vane joint and $R_{\mathrm{C}}$ is the radius of the guide way.

Substituting Eqs. (10) (14) into Eq. (9), a closed balance equation set is obtained for the lower vane, and the unknown forces $F_{\mathrm{R}, \mathrm{B}}^{\mathrm{t}}, F_{\mathrm{R}, \mathrm{B}}^{\mathrm{n}}$ and $F_{\mathrm{S}, \mathrm{B}}$ can be obtained by solving the closed equation set.

\subsection{Dynamic model of the rotor}

As shown in Fig. 4(b), when the eccentric shaft rotates clockwise with a uniform angular velocity, the rotor moves such that its centre $\mathrm{O}_{1}$ rotates around $\mathrm{O}$ while its vertical symmetry axis $\mathrm{AB}$ swings around $\mathrm{A}$. In addition 
to the reaction forces of the two vanes, an inertia force $F_{\mathrm{I}, \text { ro }}$ and three gas forces $F_{\mathrm{P}, \text { ro }}^{1}, F_{\mathrm{P}, \text { ro }}^{2}$ and $F_{\mathrm{P}, \text { ro }}^{3}$ act on the rotor centre $\mathrm{O}_{1}$. The rotor is also subject to the three resistance moments $M_{\mathrm{F}, \mathrm{e}}, M_{\mathrm{F}, \mathrm{ed}}$ and $M_{\mathrm{F}, \mathrm{ro}}$, which are respectively caused by the friction on the eccentric bearing and rotor end faces and the radial clearance between the rotor and cylinder walls.

According to the above forces and moments acting on the rotor, its rotational equation can be derived as follows,

$$
\begin{aligned}
R_{\mathrm{ro}} F_{\mathrm{S}, \mathrm{A}}^{1}-\left(\left|\mathrm{AO}_{1}\right|-h_{\mathrm{A}}\right) F_{\mathrm{S}, \mathrm{A}}^{2}= & J_{\mathrm{ro}} \alpha_{\mathrm{ro}}+\left(R_{\mathrm{ro}}-R_{\mathrm{B}}\right) \cos \left(\theta_{\mathrm{A}}+\theta_{\mathrm{B}}\right) F_{\mathrm{R}, \mathrm{B}}^{\mathrm{t}} \\
& +\left(R_{\mathrm{ro}}-R_{\mathrm{B}}\right) \sin \left(\theta_{\mathrm{A}}+\theta_{\mathrm{B}}\right) F_{\mathrm{R}, \mathrm{B}}^{\mathrm{n}}+M_{\mathrm{F}, \mathrm{e}} \\
& -M_{\mathrm{F}, \mathrm{ro}}-M_{\mathrm{F}, \mathrm{ed}}
\end{aligned}
$$

where $J_{\text {ro }}$ is the moment of inertia of the rotor around $\mathrm{O}_{1}$ and $\alpha_{\mathrm{ro}}$ is the angular acceleration of the rotor, which is equal to that of the upper vane.

During operation, the rotor and cylinder end faces are separated by an axial clearance which is filled with lubricant. Given the small axial clearance, it is assumed that the friction therein is dominated by the Couette shear. The friction force and resistance moment at each end face contact can be integrated over the friction region as shown in Fig. 5. The velocity components at the infinitesimal element are the linear velocities caused by the rotation of the rotor and eccentric shaft, respectively. It is assumed that the axial clearances at the two ends of the rotor are equivalent. The friction force and resistance moment at the rotor end faces, respectively, can be then expressed as follows,

$$
\begin{gathered}
F_{\mathrm{F}, \mathrm{ed}}=2 \int_{0}^{2 \pi} \int_{R_{\mathrm{e}}}^{R_{\mathrm{ro}}} \frac{\mu}{\delta_{\mathrm{ed}}} e \omega_{\mathrm{sh}} r \mathrm{~d} r \mathrm{~d} \lambda \\
M_{\mathrm{F}, \mathrm{ed}}=2 \int_{0}^{2 \pi} \int_{R_{\mathrm{e}}}^{R_{\mathrm{ro}}} \frac{\mu}{\delta_{\mathrm{ed}}} \omega_{\mathrm{ro}} r^{3} \mathrm{~d} r \mathrm{~d} \lambda
\end{gathered}
$$

where $\delta_{\text {ed }}$ is the axial clearance at the rotor end face, $r$ and $\lambda$ are the integration variables, $\omega_{\text {sh }}$ is the angular velocity of the shaft, $\omega_{\mathrm{ro}}$ is the angular velocity of the rotor around $\mathrm{O}_{1}, \mu$ is the dynamic viscosity of the lubricant and $R_{\mathrm{e}}$ is the radius of the eccentric. 
The resistance moment caused by the lubricant oil film at the radial clearance between the rotor and cylinder walls is expressed as follows,

$$
M_{\mathrm{F}, \mathrm{ro}}=\frac{\mu}{\delta_{\mathrm{ro}}} \theta_{\mathrm{ro}} R_{\mathrm{ro}}^{2} H\left(e \omega_{\mathrm{sh}}-R_{\mathrm{ro}} \omega_{\mathrm{ro}}\right)
$$

where $\theta_{\text {ro }}$ is the angle of the oil film.

The frictional resistance moment of the eccentric journal bearing is evaluated by the equation proposed by Hirani et al. (1997) as follows,

$$
M_{\mathrm{F}, \mathrm{e}}=\frac{\mu\left(\omega_{\mathrm{sh}}+\omega_{\mathrm{ro}}\right) R_{\mathrm{e}}^{3} L_{\mathrm{e}} \pi}{\delta_{\mathrm{e}} \sqrt{1-\varepsilon_{\mathrm{e}}^{2}}}\left(\frac{2+\varepsilon_{\mathrm{e}}}{1+\varepsilon_{\mathrm{e}}}\right)+\frac{\delta_{\mathrm{e}} \varepsilon_{\mathrm{e}} F_{\mathrm{e}} \sin \psi_{\mathrm{e}}}{2}
$$

where $L_{\mathrm{e}}$ is the length of the eccentric bearing, $\delta_{\mathrm{e}}$ is the bearing clearance, and the bearing eccentric ratio $\varepsilon_{\mathrm{e}}$ and the bearing attitude angle $\psi_{\mathrm{e}}$ can be calculated by the method proposed by Hirani et al. (1999). The radial bearing load can be obtained by summarising all of the forces acting on the rotor at $\mathrm{O}_{1}$, and its components in the $\mathrm{X}_{1}$ and $\mathrm{Y}_{1}$ directions are respectively given as follows,

$$
\left\{\begin{array}{l}
F_{\mathrm{e}}^{\mathrm{x}}=F_{\mathrm{P}, \mathrm{ro}}^{\mathrm{x}}-F_{\mathrm{S}, \mathrm{A}}^{1}+F_{\mathrm{S}, \mathrm{A}}^{2}-\cos \left(\theta_{\mathrm{A}}+\theta_{\mathrm{B}}\right) F_{\mathrm{R}, \mathrm{B}}^{\mathrm{t}}-\sin \left(\theta_{\mathrm{A}}+\theta_{\mathrm{B}}\right) F_{\mathrm{R}, \mathrm{B}}^{\mathrm{n}}+\sin \left(\varphi+\theta_{\mathrm{A}}\right) F_{\mathrm{I}, \mathrm{ro}}-\cos \left(\varphi+\theta_{\mathrm{A}}\right) F_{\mathrm{F}, \mathrm{ed}} \\
F_{\mathrm{e}}^{\mathrm{y}}=F_{\mathrm{P}, \mathrm{ro}}^{\mathrm{y}}+F_{\mathrm{F}, \mathrm{A}}^{1}+F_{\mathrm{F}, \mathrm{A}}^{2}+\sin \left(\theta_{\mathrm{A}}+\theta_{\mathrm{B}}\right) F_{\mathrm{R}, \mathrm{B}}^{\mathrm{t}}-\cos \left(\theta_{\mathrm{A}}+\theta_{\mathrm{B}}\right) F_{\mathrm{R}, \mathrm{B}}^{\mathrm{n}}+\cos \left(\varphi+\theta_{\mathrm{A}}\right) F_{\mathrm{I}, \mathrm{ro}}+\sin \left(\varphi+\theta_{\mathrm{A}}\right) F_{\mathrm{F}, \mathrm{ed}}
\end{array}\right.
$$

where the rotor inertia force is expressed as,

$$
F_{\mathrm{I}, \mathrm{ro}}=m_{\mathrm{ro}} e \omega_{\mathrm{ro}}^{2}
$$

where $m_{\mathrm{ro}}$ is the mass of the rotor. The components of the resultant pressure force on the rotor in the $\mathrm{X}_{1}$ and $\mathrm{Y}_{1}$ directions can be expressed as follows,

$$
\left\{\begin{array}{l}
F_{\mathrm{P}, \mathrm{ro}}^{\mathrm{x}}=-2 R_{\mathrm{ro}} H\left[p_{1} \sin ^{2} \frac{\beta_{1}}{2}+p_{2} \sin \frac{\beta_{2}}{2} \sin \left(\frac{\beta_{2}}{2}-\gamma\right)-p_{3} \sin ^{2} \frac{\beta_{3}}{2}\right] \\
F_{\mathrm{P}, \mathrm{ro}}^{\mathrm{y}}=-2 R_{\mathrm{ro}} H\left[p_{1} \sin \frac{\beta_{1}}{2} \cos \frac{\beta_{1}}{2}-p_{2} \sin \frac{\beta_{2}}{2} \cos \left(\frac{\beta_{2}}{2}-\gamma\right)+p_{3} \sin \frac{\beta_{3}}{2} \cos \frac{\beta_{3}}{2}\right]
\end{array}\right.
$$

where $\gamma$ is the included angle between $\mathrm{O}_{1} \mathrm{~B}$ and $\mathrm{O}_{1} \mathrm{I}$, and $\beta_{1}, \beta_{2}$ and $\beta_{3}$ are the arc angles for chambers 1,2 and 3, respectively. 


\subsection{Mechanical efficiency}

The shaft power consumption of the DSVC consists of the indicated power consumed by the gas compression and the mechanical loss caused by friction. The mechanical efficiency is given as the ratio of the indicated power to the shaft power as follows,

$$
\eta_{\mathrm{m}}=\frac{P_{\mathrm{i}}}{P_{\mathrm{sh}}}
$$

where the shaft power can be calculated by averaging the instant power in a shaft revolution as follows,

$$
P_{\mathrm{sh}}=\frac{\omega_{\mathrm{sh}}}{2 \pi} \int_{0}^{2 \pi} M_{\mathrm{sh}} \mathrm{d} \varphi
$$

where the resistance moment on the shaft is expressed as follows,

$$
M_{\mathrm{sh}}=e\left[\sin \left(\varphi+\theta_{\mathrm{A}}\right) F_{\mathrm{e}}^{\mathrm{y}}-\cos \left(\varphi+\theta_{\mathrm{A}}\right) F_{\mathrm{e}}^{\mathrm{x}}\right]+M_{\mathrm{F}, \mathrm{sh}}+M_{\mathrm{F}, \mathrm{e}}
$$

where $M_{\mathrm{F}, \mathrm{sh}}$ is the moment caused by the friction of two shaft journal bearings, which can be calculated by using the friction model for journal bearings formulated by Eq. (19) with the geometrical parameters and angular velocity replaced by those for the shaft bearings. The bearing load on the shaft bearings is evaluated as follows,

$$
\left\{\begin{array}{l}
F_{\mathrm{sh}}^{\mathrm{x}}=F_{\mathrm{e}}^{\mathrm{x}} \cos \theta_{\mathrm{A}}-F_{\mathrm{e}}^{\mathrm{y}} \sin \theta_{\mathrm{A}}+F_{\mathrm{I}, \mathrm{e}} \sin \varphi \\
F_{\mathrm{sh}}^{\mathrm{y}}=F_{\mathrm{e}}^{\mathrm{x}} \sin \theta_{\mathrm{A}}+F_{\mathrm{e}}^{\mathrm{y}} \cos \theta_{\mathrm{A}}+F_{\mathrm{I}, \mathrm{e}} \cos \varphi
\end{array}\right.
$$

where $F_{\mathrm{I}, \mathrm{e}}$ is the inertia force of the eccentric. The indicated power is equal to the power consumed by the gas compression. Neglecting the pressure loss during suction and discharge, the leakage loss and heat transfer, the indicated power for the adiabatic compression can be expressed as,

$$
P_{\mathrm{i}}=\frac{\omega_{\mathrm{sh}} p_{\mathrm{s}} V_{\max }}{\pi} \frac{k}{k-1}\left[\left(\frac{p_{\mathrm{d}}}{p_{\mathrm{s}}}\right)^{\frac{k-1}{k}}-1\right]
$$

where $k$ is the adiabatic exponent, $p_{\mathrm{s}}$ is the suction pressure and $p_{\mathrm{d}}$ is the discharge pressure.

As mentioned, friction losses mainly occur at the sides and joint contacts of the two vanes, the radial and axial clearances between the rotor and cylinder, and the three journal bearings. For each frictional coupling, the modelled frictional force or moment can be used to evaluate the friction loss based on the simulation of the 
dynamic models. The frictional loss at each frictional coupling is formulated as the product of the frictional force and relative velocity or the product of the frictional moment and relative angular velocity as follows

$$
\begin{gathered}
P_{\mathrm{F}}=F_{\mathrm{F}} v_{\mathrm{r}} \\
P_{\mathrm{F}}=M_{\mathrm{F}} \omega_{\mathrm{r}}
\end{gathered}
$$

\section{Results and discussion}

\subsection{Simulation results of the dynamic models}

Using the established models, the forces and moments acting on the components in the DSVC were simulated in a shaft revolution, and the results can be used to analyse the dynamic characteristics and mechanical efficiency of the mechanism. The dynamic simulations were implemented on the DSVC prototype whose operating specifications and main dimensions are presented in Table 1.

Fig. 6 and Fig. 7 show the simulated results of the forces acting on the upper vane and lower vane, respectively. It can be observed that the magnitudes of all of the forces fluctuate during a shaft revolution. For the upper vane, as shown in Fig. 6, as the magnitude of the pressure force peaks at a shaft angle of around $4 \pi / 3$, the other forces acting on the vane sides and vane joint peak at the same shaft angle. It can be observed that the restriction forces of the vane slot remain positive throughout the shaft revolution. This means that the two sides of the upper vane maintain contact with the vane slot and thus the upper vane is always being cantilevered. For the lower vane, as shown in Fig. 7, the magnitude of the pressure force peaks at a shaft angle of around $\pi / 3$, which results in peaks for the other forces on the vane sides and vane joint. The positive restriction forces of the guide way mean that the lower vane is always in contact with one side of the guide way throughout the shaft revolution. 
Fig. 8 shows the pressure force and the radial loads on the eccentric bearing and shaft bearings during a shaft revolution. It can be seen that the pressure force presents two peaks within a shaft revolution due to the alternate changes in pressure in the left and right work chambers. The relevant shaft angles for the two peak values correspond to those for the pressure forces acting on the upper vane and lower vane, respectively. As shown in Fig. 8, the radial loads on the eccentric bearing and shaft bearings are almost equivalent, and the fluctuations in the loads are dominated by the pressure force and peak values during a shaft revolution. The first peak value is about $1.55 \mathrm{kN}$, which is little higher than the later peak value of $1.47 \mathrm{kN}$. Referring to Eq.(25), because the resistance moment of the shaft is dominated by the radial force on the eccentric, it can be deduced that the variation in the radial loads on the eccentric bearing also causes a fluctuation with two peaks in the resistance moment on the shaft. This is discussed further in section 4.3.

\subsection{Friction loss analysis}

Under the operating conditions shown in Table 1, the calculated shaft power of the DSVC prototype is $886.3 \mathrm{~W}$, while the calculated indicated power is $822.8 \mathrm{~W}$, which corresponds to a mechanical efficiency of $92.8 \%$. Accordingly, 63.5 W of mechanical loss is caused by the friction in the mechanism. In this section, the components of the friction loss in the DSVC are analysed to determine the main factors that influence the mechanical efficiency.

Table 2 shows the simulated results of the average friction losses at various friction couplings. It can be observed that the friction losses at the eccentric and shaft bearings, respectively, comprise $34 \%$ and $29 \%$ of the total friction loss, which means that the bearing friction is the most dominant source of friction loss in the DSVC.

Referring to Fig. 8, it can be observed that the radial loads on the eccentric bearing and the shaft bearings are almost equivalent. However, due to the larger radius of the eccentric bearing, the friction loss at the eccentric bearing is clearly higher than that at the shaft bearings. In addition to the journal bearing friction, the vane side 
friction and end face friction also cause significant friction loss. As shown in Table 2, the proportions of friction losses at the upper vane side and lower vane side are, respectively, $16.2 \%$ and $4.3 \%$. Fig. 9 shows the sliding velocities of the upper and lower vane. At the upper vane sides, significant friction loss results from the considerable sliding velocity and contact forces. At the lower vane sides, although the sliding velocity is a little higher than that of the upper vane, the friction loss is only a quarter of that of the upper vane due to the smaller contact force. Compared to the vane sides, as shown in Table 2, the friction losses at the joints of the upper and lower vanes and the guide way are comparatively small. This is a result of the lower linear velocity at the vane joints and guide way, as shown in Fig. 10, and the lower friction coefficient due to the condition of the well lubricant. It is also found that among the three joint contacts, the lower vane joint causes much more friction loss than the other two joints due to the higher linear velocity during operation. As shown in Table 2 , the friction losses caused by the liquid shear at the end face clearances and radial clearance, respectively, are $10.5 \%$ and $1.3 \%$ of the total friction loss. The significant end face friction results from the considerable area of friction and the small axial clearance between the rotor and cylinder end faces. From the above analysis, it can be concluded that the dominant sources of friction loss in the DSVC include the journal bearing friction and friction at the upper vane sides and rotor end faces. The friction loss directly related to the lower vane is only about $7.8 \%$ of the total friction loss.

Because the DSVC is required to operate at a wide range of rotating speeds, it is worth analysing the status of its mechanical efficiency at different shaft speeds. Fig. 11 shows the variations of non-dimensional friction loss (the ratio of friction loss to shaft power) and mechanical efficiency with the shaft speed. It can be observed that as the shaft speed increases from $1000 \mathrm{rpm}$ to $4000 \mathrm{rpm}$, the mechanical efficiency decreases from $96.1 \%$ to $91.1 \%$ due to the increased friction loss. From the variations in the non-dimensional friction losses shown in Fig.11, it can be deduced that the increase in the total friction loss of the DSVC mainly results from the increases in the 
non-dimensional friction losses at the eccentric bearing, shaft bearings and rotor end faces. Because the non-dimensional friction losses at the upper and lower vane sides change very little, it can be deduced that their increases make a small contribution to the increase in the total friction loss. Thus, it can be concluded that the friction losses at the eccentric bearing, shaft bearings and rotor end faces are sensitive to the shaft speed. Therefore, in high speed applications, the parameters of the journal bearings and rotor end face are critical for improving the mechanical efficiency of the DSVC.

\subsection{Comparative analysis of the DSVC and SVC}

In the DSVC, a lower vane assembly is added to the SVC design, which results in an increase in the work capacity of the compressor under the same operating specifications and dimensions. However, the lower vane also induces additional friction loss and affects the dynamics of the other components. To assess the design of the DSVC, in this section, a comparative analysis of the dynamics of the DSVC and the SVC is presented.

Table 3 shows a comparison of the power consumption of the DSVC and SVC, both of which have the same operating specifications and dimensions as given in Table 1. It can be observed that compared to the SVC, the friction loss in the DSVC increases by $8.9 \%$. However, due to the increase in the work capacity of the DSVC, the indicated power of the DSVC increases by more than $63.6 \%$. Thus, the mechanical efficiency of the DSVC is greater than that of the SVC. As shown in Table 3, there are small decreases in the friction losses at the upper vane sides and vane joint for the DSVC, whereas the friction losses at the rotor end faces and radial clearance are the same for the DSVC and SVC. At the eccentric bearing and shaft bearings, there are small increases in friction loss for the DSVC. The difference between the total friction losses of the DSVC and the SVC is $5.2 \mathrm{~W}$, which is approximately equal to the friction loss caused by the lower vane assembly $(4.9 \mathrm{~W})$. This indicates that although the lower vane induces additional friction loss for the DSVC, the lower vane assembly has negligible effect on the friction losses of the other components. 
Because the DSVC and SVC have the same operating specifications and dimensions, the motion of the components is the same in the two models. Accordingly, it can be deduced that the average values of the forces acting on the upper vane in the DSVC and SVC are approximately the same. The variations in the forces acting on the upper vane in the DSVC are also similar to those in the SVC, as shown in the simulated results in (Hu et al., 2013). However, as shown in Fig. 12, the pressure forces acting on the rotor in the DSVC and SVC are completely different. The fluctuation period of the pressure force in the SVC is $2 \pi$, which is twice that of the pressure force in the DSVC. The amplitude of the force fluctuation for the SVC is also larger than that of the DSVC. Because the radial loads on the eccentric and shaft bearings are related to the pressure force on the rotor, it can be concluded that the loading conditions on the eccentric and shaft bearings in the DSVC are relatively better than those in the SVC. Moreover, as shown in Fig. 13, the difference between the pressure forces on the rotor corresponds to the difference between the resistance moments for the DSVC and SVC. It can be seen that for the DSVC, the resistance moment presents two peaks during a shaft revolution and the fluctuation amplitude is about $4.76 \mathrm{Nm}$. For the $\mathrm{SVC}$, the resistance moment presents one peak during a shaft revolution and the fluctuation amplitude is about $5.83 \mathrm{Nm}$. This means that during operation, the nonuniformity of the shaft power consumption in the DSVC is smaller than that in the SVC, which means that the DSVC operates more smoothly.

\section{Conclusions}

The structural design and work principles of the DSVC are presented in this paper. The dynamic characteristics and mechanical efficiency of the DSVC are theoretically analysed based on a simulation of the established dynamic model. A comparative analysis of the dynamics of the DSVC and SVC is also conducted to assess the design of the DSVC.

Compared to the SVC, the new double-swing vane structure of the DSVC significantly increases its work capacity. Under the same operating conditions and dimensions, the theoretical suction volume of the DSVC is 
about 1.6 times that of the SVC, which suggests that the DSVC can be constructed with a smaller volume and lighter weight.

The calculated mechanical efficiency of the DSVC prototype is $92.8 \%$ at a shaft speed of $3000 \mathrm{rpm}$. The dominant sources of friction loss in the DSVC include the friction at the journal bearings, upper vane sides and rotor end faces. The friction loss directly related to the lower vane is only about $7.8 \%$ of the total friction loss. As the shaft speed increases, the mechanical efficiency of the DSVC decreases due to the increased proportions of friction loss at the eccentric bearing, shaft bearings and rotor end faces. Although the lower vane induces additional friction loss, the mechanical efficiency of the DSVC is higher than that of the SVC under the same operating conditions and dimensions. The effect of the lower vane assembly on the friction loss of the other components is also negligible.

Moreover, the design of the double-swing vanes in the DSVC has a significant effect on the pressure forces on the rotor. Due to the smaller fluctuations in the pressure forces, the loading conditions on the eccentric and shaft bearings in the DSVC are relatively better than those in the SVC. This also reduces the fluctuation in the resistance moment on the shaft, which enhances the smoothness of the compressor's operation.

After assessing the design and dynamics of the DSVC, it can be summarised that the DSVC has the advantages of higher efficiency, light weight and simple component geometries, which make it well suited for application in electric vehicle air conditioning systems. As a further step, investigation of the thermodynamic performance is recommended to guide the practical development of this compressor. This work will be reported in a future paper.

\section{Funding}

This work was supported by the National Natural Science Foundation of China (NSFC) [grant No. 51406150]; the National Science Foundation for Post-doctoral Scientists of China [Grant No. 2013M542348]. 


\section{Nomenclature}

$a_{\mathrm{r}} \quad$ Relative acceleration $\left[\mathrm{m} \mathrm{s}^{-2}\right]$

$e \quad$ eccentricity $[\mathrm{m}]$

$F_{\mathrm{F}} \quad$ Friction force $[\mathrm{N}]$

$F_{\mathrm{I}} \quad$ Inertia force $[\mathrm{N}]$

$F_{\mathrm{P}} \quad$ Pressure force $[\mathrm{N}]$

$F_{\mathrm{R}} \quad$ Restriction force [N]

$F_{\mathrm{S}} \quad$ Force on vane side $[\mathrm{N}]$

$H \quad$ Length of rotor [m]

$h \quad$ Length of vane [m]

$J \quad$ Moment of inertia $\left[\mathrm{kg} \mathrm{m}^{2}\right]$

$k \quad$ Adiabatic exponent [-]

$L_{\mathrm{e}} \quad$ Bearing length [m]

$M_{\mathrm{F}} \quad$ Frictional moment $[\mathrm{Nm}]$

$M_{\mathrm{sh}} \quad$ Resistance moment of shaft [Nm]

$m \quad$ Mass [kg]

$P_{\mathrm{i}} \quad$ Indicated power [W]

$P_{\text {sh }} \quad$ Shaft power [W]

$p \quad$ Pressure $[\mathrm{Pa}]$

$R \quad$ Radius [m]

$r \quad$ Distance between vane centroid and joint center [m]

$V_{\max } \quad$ Maximum suction volume $\left[\mathrm{m}^{3}\right]$ 
$v_{\mathrm{r}} \quad$ Relative velocity $\left[\mathrm{m} \mathrm{s}^{-1}\right]$

$\alpha \quad$ Angular acceleration $\left[\mathrm{rad} \mathrm{s}^{-2}\right]$

$\beta \quad$ Arc angle of chamber [rad]

$\delta \quad$ Clearance $[\mathrm{m}]$

$\varepsilon \quad$ Bearing eccentric ratio $[\mathrm{m}]$

$\eta_{\mathrm{F}} \quad$ Non-dimensional friction loss [\%]

$\eta_{\mathrm{J}} \quad$ Friction coefficient at vane joint [-]

$\eta_{\mathrm{S}} \quad$ Friction coefficient at vane side [-]

$\eta_{\mathrm{m}} \quad$ Mechanical efficiency[\%]

$\theta \quad$ Angular displacement [rad]

$\theta_{\text {ro }} \quad$ Angle of oil film at rotor radial clearance [rad]

$\mu \quad$ Dynamic viscosity of lubricant [Pa s]

$\varphi \quad$ Shaft angle [rad]

$\psi \quad$ Attitude angle of bearing [rad]

$\omega \quad$ Angular velocity [ $\left.\mathrm{rad} \mathrm{s}^{-1}\right]$

Subscripts and superscripts
A of joint A or upper vane
B of joint B or lower vane
C of guide way
cy of cylinder
e of eccentric
ed of end face 


$\begin{array}{ll}\text { ro } & \text { of rotor } \\ \text { sh } & \text { of shaft } \\ \mathrm{n} & \text { in normal direction } \\ \mathrm{t} & \text { in tangent direction }\end{array}$

\section{References}

Cuevas, C., Fonseca, N., Lemort, V., 2012. Automotive electric scroll compressor: Testing and modeling. International Journal of Refrigeration 35, 841-849. http://dx.doi.org/10.1016/j.ijrefrig.2011.11.019

Cuevas, C., Winandy, E., Lebrunb, J., 2008. Testing and modelling of an automotive wobble plate compressor. International Journal of Refrigeration 31, 423-431. http://dx.doi.org/10.1016/j.ijrefrig.2007.07.008

Hirani, H., Athre, K., Biswas, S., 1999. Dynamically loaded finite length journal bearings: Analytical method of solution. Journal of Tribology-Transactions of the Asme 121, 844-852. http://dx.doi.org/10.1115/1.2834144

Hirani, H., Rao, T.V.V.L.N., Athre, K., Biswas, S., 1997. Rapid performance evaluation of journal bearings. Tribology International 30, 825-834. http://dx.doi.org/10.1016/S0301-679x(97)00066-2

Hu, X., Qu, Z., Yang, X., Sun, J., 2013. Theoretical study on frictional losses of a novel automotive swing vane compressor. International Journal of Refrigeration 36, 758-767. http://dx.doi.org/10.1016/j.ijrefrig.2012.11.001

Nam, D., Lee, P., Lee, G., Kwon, Y., Lee, J., 2015. Optimization of an oil charge amount on electric driven scroll compressor for eco-friendly vehicle. International Journal of Refrigeration 57, 54-61. http://dx.doi.org/10.1016/j.ijrefrig.2015.05.009

Qi, Z., 2014. Advances on air conditioning and heat pump system in electric vehicles - A review. Renewable and Sustainable Energy Reviews 38, 754-764. http://dx.doi.org/10.1016/j.rser.2014.07.038 
Teh, Y.L., Ooi, K.T., 2009. Theoretical study of a novel refrigeration compressor - Part I: Design of the revolving vane (RV) compressor and its frictional losses. International Journal of Refrigeration 32, 1092-1102. http://dx.doi.org/10.1016/j.ijrefrig.2008.09.006

Tian, C., Dou, C., Yang, X., Li, X., 2004. A mathematical model of variable displacement wobble plate compressor for automotive air conditioning system. Applied Thermal Engineering 24, 2467-2486. http://dx.doi.org/10.1016/j.applthermaleng.2004.04.011

Tian, C., Liao, Y., Li, X., 2006. A mathematical model of variable displacement swash plate compressor for automotive air conditioning system. International Journal of Refrigeration 29, 270-280. http://dx.doi.org/10.1016/j.ijrefrig.2005.05.002

Wang, Z., MingshanWei, Peng, F., Liu, H., Guo, C., Tian, G., 2016. Experimental evaluation of an integrated electric vehicle AC/HP system operating with R134a and R407C. Applied Thermal Engineering 100, 1179-1188. http://dx.doi.org/10.1016/j.applthermaleng.2016.02.064

Yanagisawa, T., Shimizu, T., 1985. Friction losses in rolling piston type rotary compressors III. International Journal of Refrigeration 8, 159-165. http://dx.doi.org/10.1016/0140-7007(85)90156-2

Zhang, Y., Wang, W., 2012. Using overflow in a swash plate compressor for automotive air conditioning system. Proc. IMechE Part A: Journal of Power and Energy 226, 564-579. http://dx.doi.org/10.1177/0957650911433249 


\section{Table captions}

Table 1 Operating specifications and main dimensions of the DSVC prototype.

Table 2 Simulation results of the friction losses at various friction couplings.

Table 3 Comparison of the power consumption in the DSVC and SVC.

\section{Figure captions}

Fig. 1 Schematic of the DSVC: (a) sectional view, (b) cutaway view and (c) axonometric view.

Fig. 2 Schematic of the work principle of the DSVC.

Fig. 3 Variations of element volume and pressure in a work cycle for the former and latter chambers.

Fig. 4 Forces acting on (a) the upper and lower vanes, (b) the rotor.

Fig. 5 Definition of the velocity at the infinitesimal element on the rotor end face.

Fig. 6 Simulated forces acting on the upper vane during a shaft revolution.

Fig. 7 Simulated forces acting on the lower vane during a shaft revolution.

Fig. 8 Simulated radial loads for the eccentric bearing and shaft bearings during a shaft revolution.

Fig. 9 Sliding velocities for the upper and lower vanes.

Fig. 10 Relative linear velocities for the joints of the upper and lower vanes and the guide way.

Fig. 11 Variations in the friction losses and mechanical efficiency with the shaft speed.

Fig. 12 Comparison of the pressure forces on the rotor for the DSVC and SVC.

Fig. 13 Comparison of the resistance moments for the DSVC and SVC. 

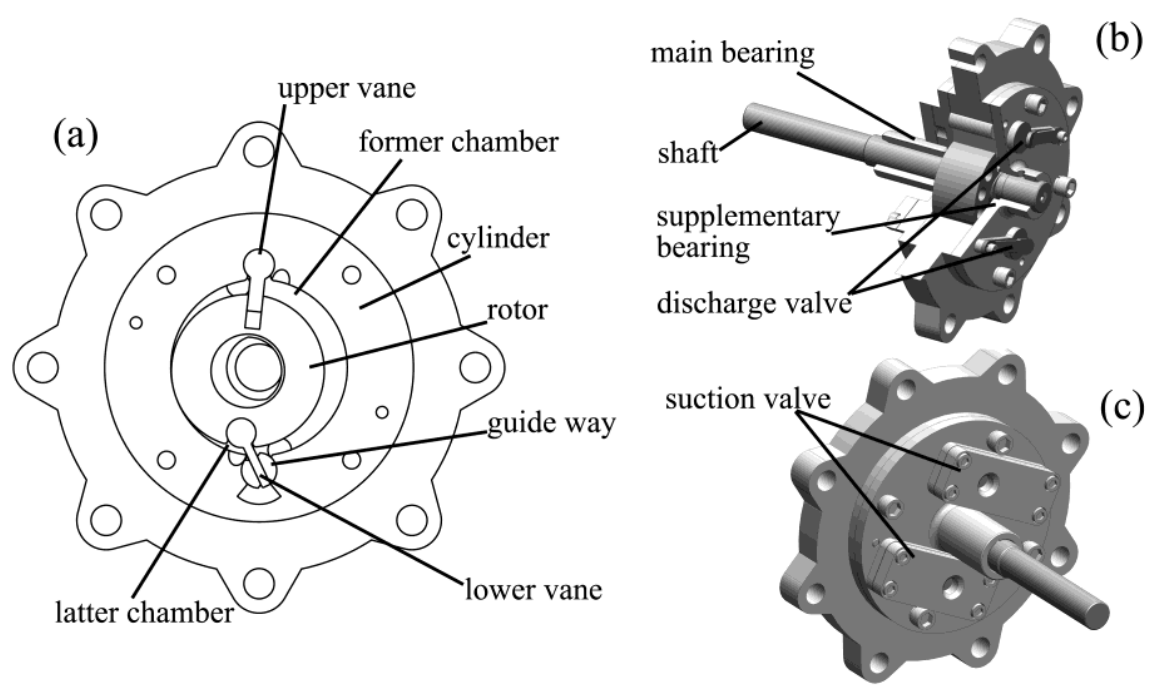


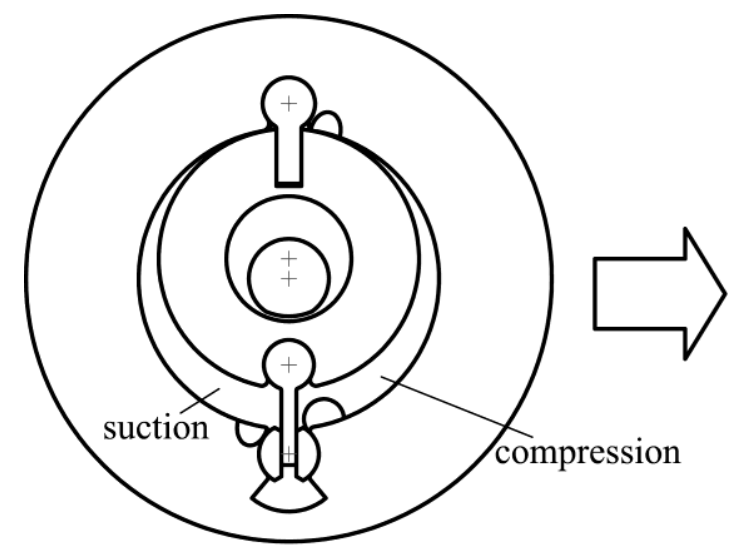

(a) $\varphi=0$

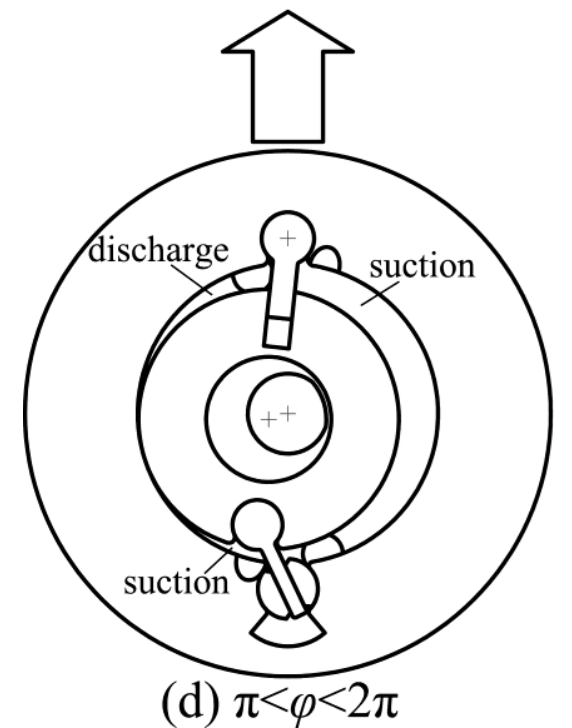

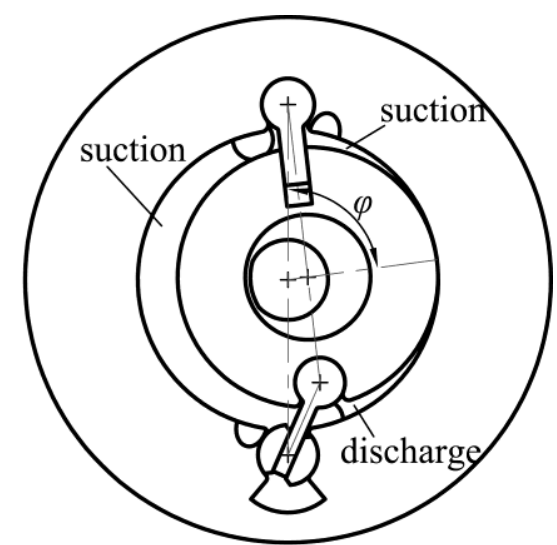

(b) $0<\varphi<\pi$

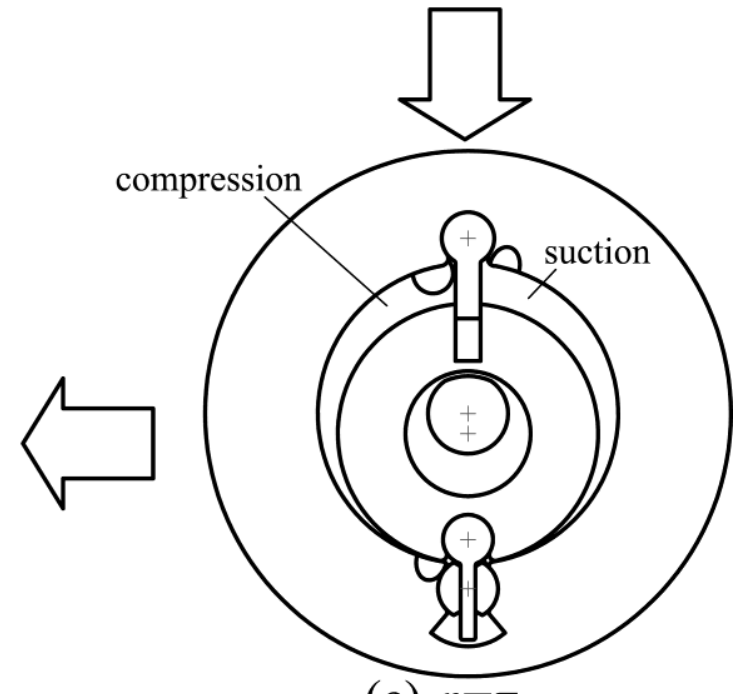

(c) $\varphi=\pi$ 


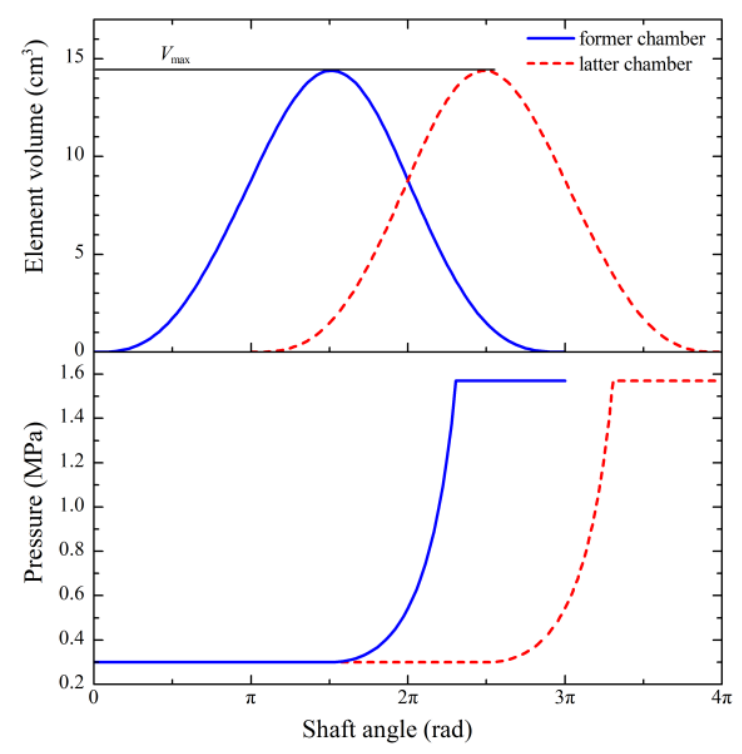




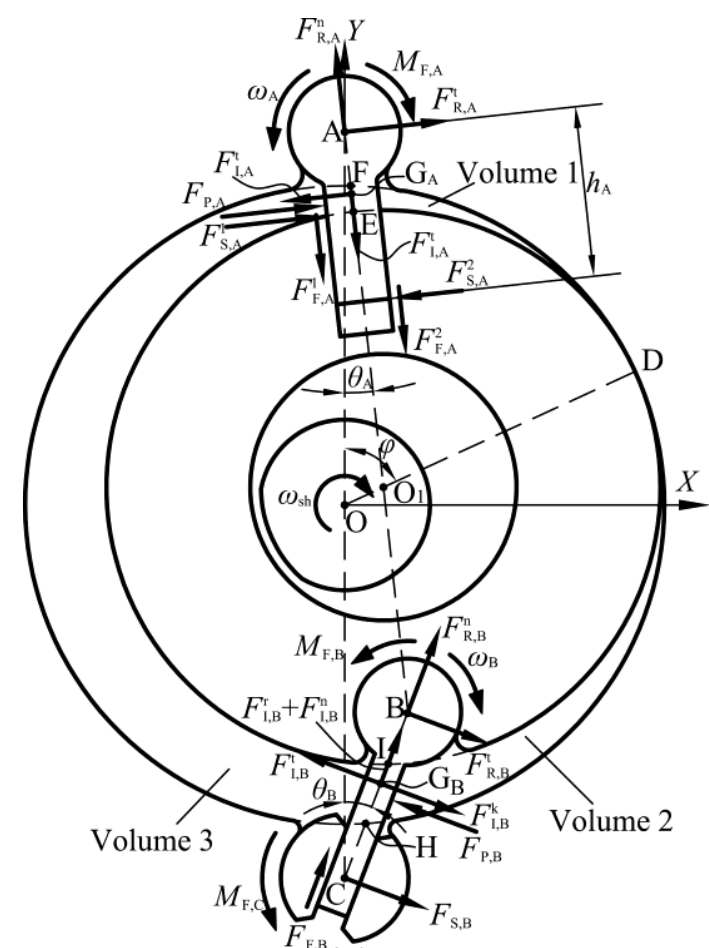

(a)

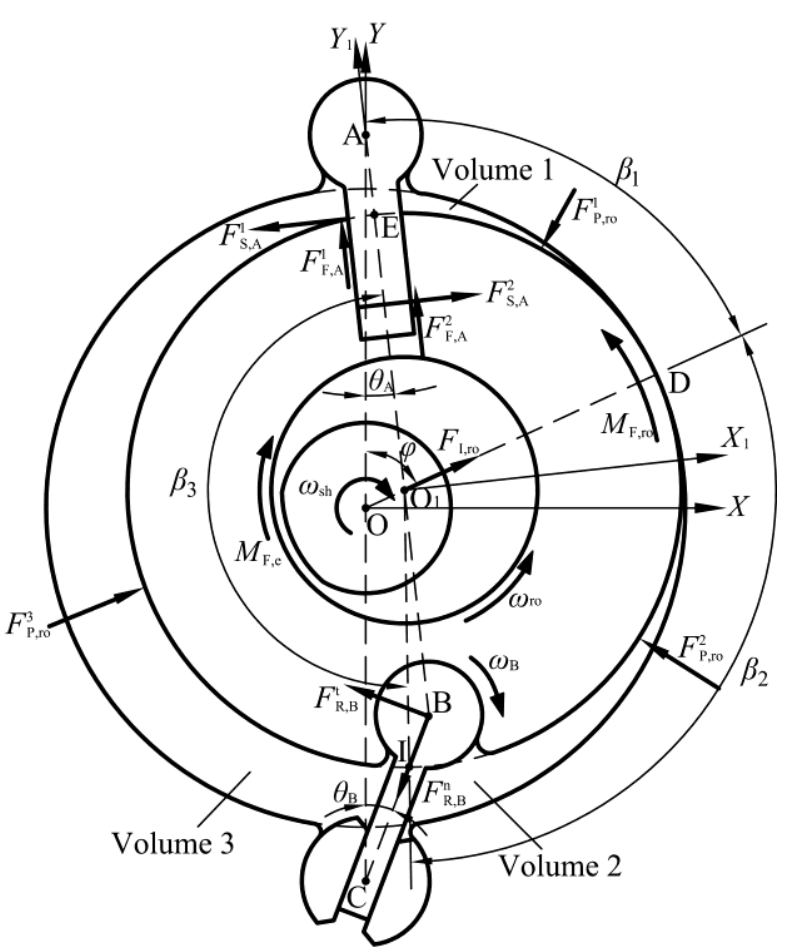

(b) 


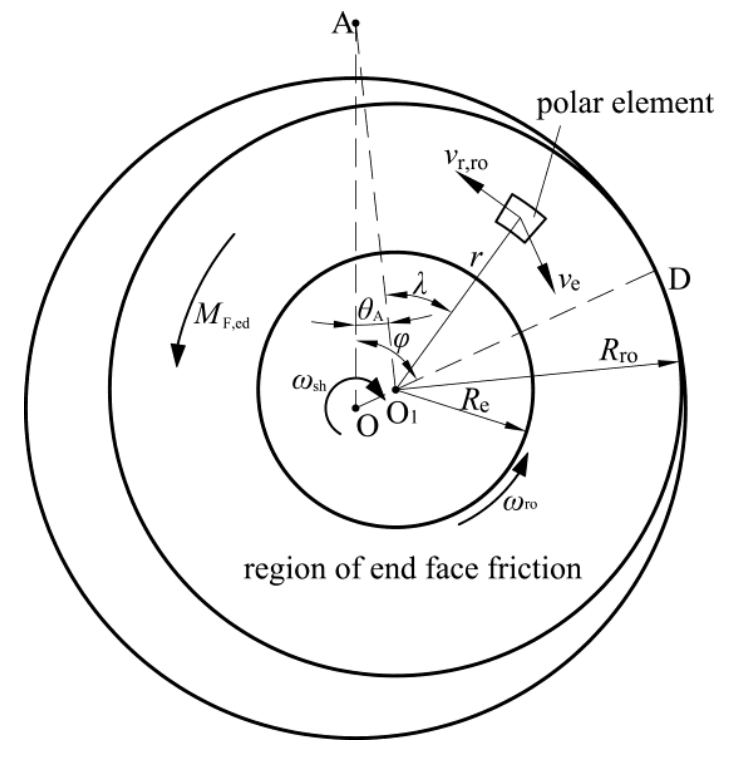




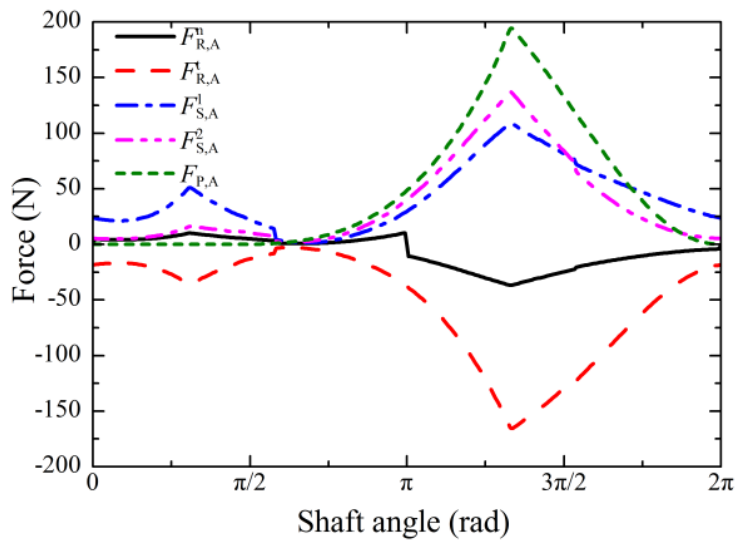




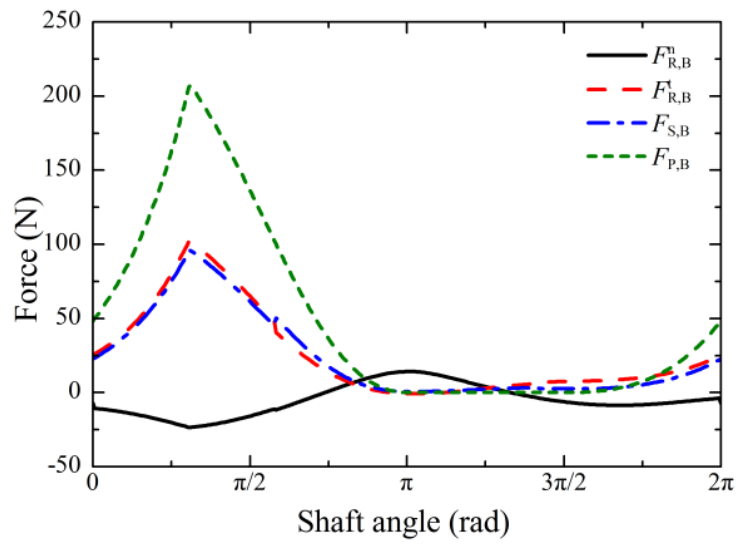




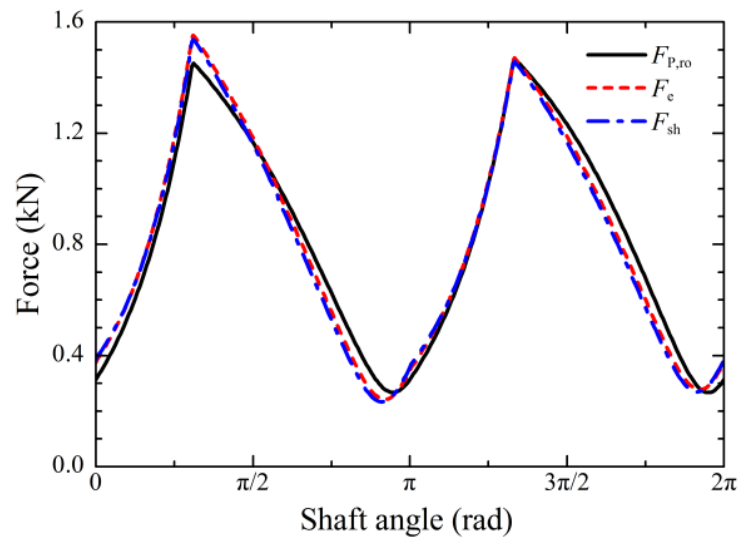




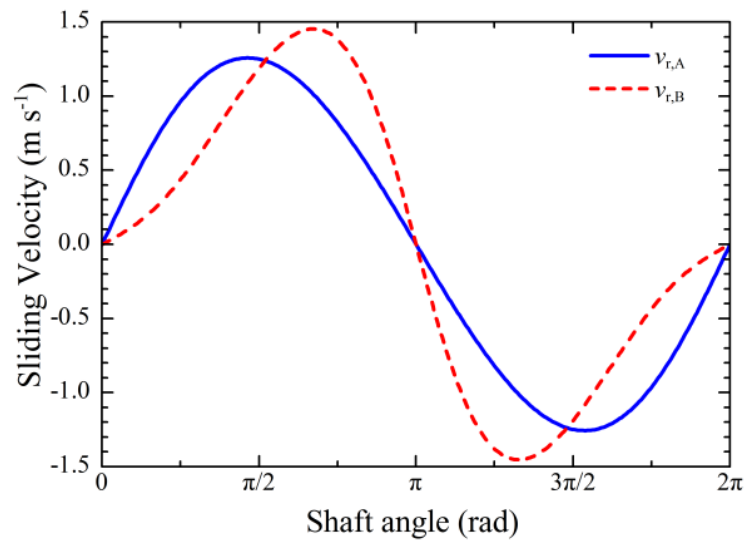




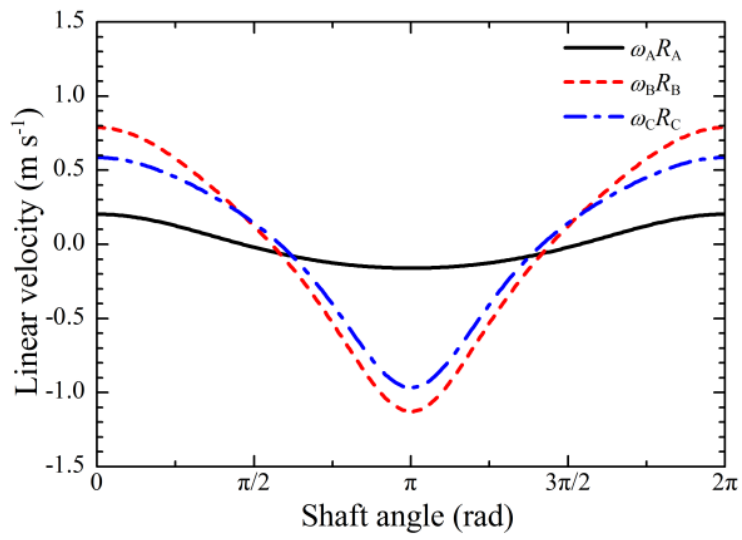




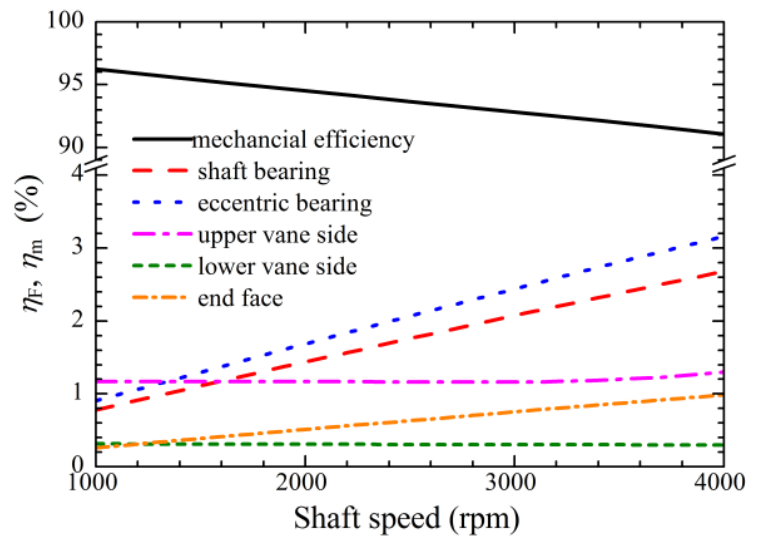




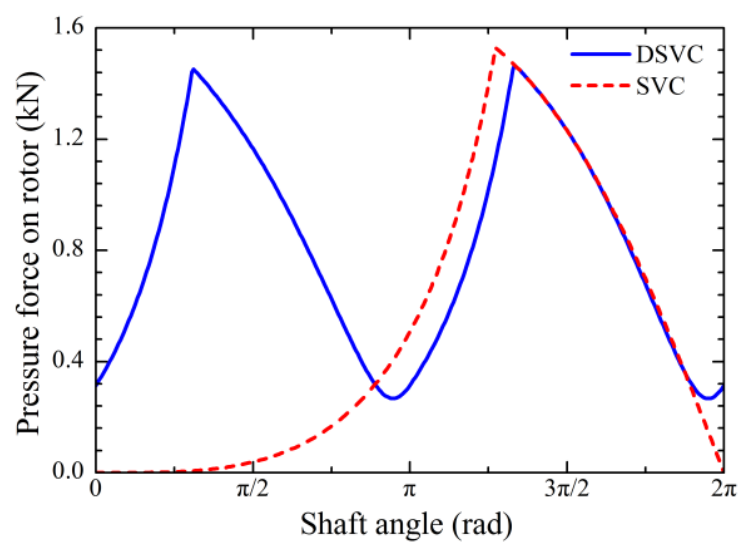




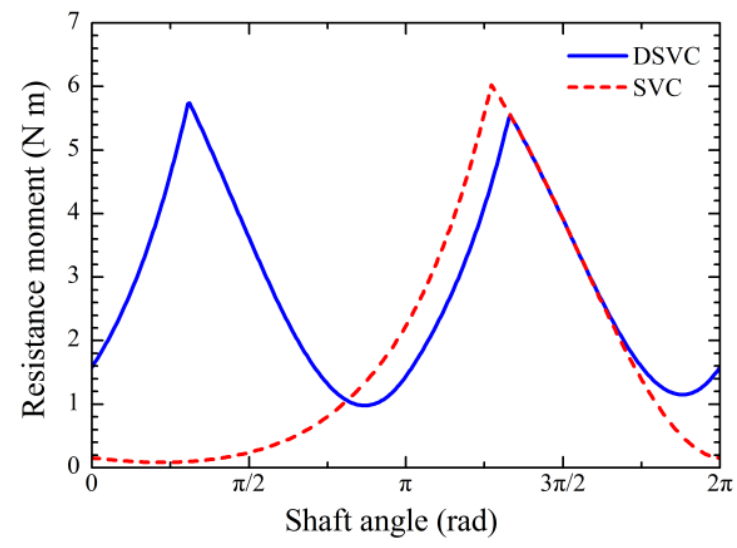


Table 1 Operating specifications and main dimensions of the DSVC prototype.

\begin{tabular}{ll}
\hline Operating specifications & \\
\hline Working fluid & R134a \\
Suction pressure & $0.3 \mathrm{MPa}$ \\
Discharge pressure & $1.57 \mathrm{MPa}$ \\
Shaft speed & $3000 \mathrm{rev} / \mathrm{min}$ \\
Lubricant viscosity & $10.8 \mathrm{mPa}$ \\
Adiabatic exponent & 1.2 \\
\hline Main dimensions & \\
\hline Rotor radius & $26 \mathrm{~mm}$ \\
Rotor length & $25 \mathrm{~mm}$ \\
Cylinder radius & $30 \mathrm{~mm}$ \\
Upper vane length & $21 \mathrm{~mm}$ \\
Upper vane joint radius & $5 \mathrm{~mm}$ \\
Lower vane length & $22 \mathrm{~mm}$ \\
Lower vane joint radius & $5 \mathrm{~mm}$ \\
Guide way radius & $6.5 \mathrm{~mm}$ \\
End face clearance & $10 \mu \mathrm{m}$ \\
Eccentric bearing radius & $12 \mathrm{~mm}$ \\
Eccentric bearing length & $23 \mathrm{~mm}$ \\
Radial clearance of eccentric bearing & $13 \mu \mathrm{m}$ \\
Main bearing radius & $8 \mathrm{~mm}$ \\
Main bearing length & $45 \mathrm{~mm}$ \\
Radial clearance of main bearing & $13 \mu \mathrm{m}$ \\
Supplementary bearing radius & $8 \mathrm{~mm}$ \\
Supplementary bearing length & $21 \mathrm{~mm}$ \\
Radial clearance of supplementary bearing & $13 \mu \mathrm{m}$ \\
\hline
\end{tabular}


Table 2 Simulation results of the friction losses at various friction couplings

\begin{tabular}{lcc}
\hline Friction coupling & $\begin{array}{c}\text { Friction loss } \\
(\mathrm{W})\end{array}$ & $\begin{array}{c}\text { Percentage } \\
(\%)\end{array}$ \\
\hline Upper vane sides & 10.3 & 16.2 \\
Upper vane joint & 0.5 & 0.8 \\
Lower vane sides & 2.7 & 4.3 \\
Lower vane joint & 1.4 & 2.2 \\
Guide way joint & 0.8 & 1.3 \\
Rotor end faces & 6.7 & 10.5 \\
Rotor radial clearance & 1.1 & 1.7 \\
Eccentric bearing & 21.6 & 34.0 \\
Shaft bearings & 18.4 & 29.0 \\
Total & 63.5 & \\
\hline
\end{tabular}


Table 3 Comparison of the power consumption in the DSVC and SVC

\begin{tabular}{lllll}
\hline \multicolumn{1}{c}{ Power consumption } & SVC & DSVC & Difference \\
\hline Upper vane sides & 10.4 & 10.3 & -0.1 \\
Upper vane joint & 0.6 & 0.5 & -0.1 \\
Lower vane sides & 0 & 2.7 & 2.7 \\
& Lower vane joint & 0 & 1.4 & 1.4 \\
Friction & Guide way joint & 0 & 0.8 & 0.8 \\
loss (W) $\quad$ Rotor end faces & 6.7 & 6.7 & 0 \\
& Rotor radial & 1.1 & 1.1 & 0 \\
& clearance & & & \\
& Eccentric bearing & 21.4 & 21.6 & 0.2 \\
& Shaft bearings & 18.1 & 18.4 & 0.3 \\
\hline Total friction loss (W) & 58.3 & 63.5 & 5.2 \\
Indicated power (W) & 502.9 & 822.8 & 319.9 \\
Shaft power (W) & 562.2 & 886.3 & 324.1 \\
Mechanical efficiency (\%) & 89.6 & 92.8 & 3.2 \\
\hline
\end{tabular}

